\section{$\underset{\substack{\text { hommes } \\ \text { \& migrations }}}{ }$}

\section{Hommes \& migrations}

Revue française de référence sur les dynamiques

migratoires

1317-1318 | 2017

L'Europe en mouvement

\title{
Gaël Faye, Petit pays
}

Paris, Grasset, 2016, 217 p., $18 €$.

\section{Mustapha Harzoune}

\section{(2) OpenEdition}

\section{Journals}

\section{Édition électronique}

URL : http://journals.openedition.org/hommesmigrations/3937

DOI : 10.4000/hommesmigrations.3937

ISSN : 2262-3353

\section{Éditeur}

Musée national de l'histoire de l'immigration

\section{Édition imprimée}

Date de publication : 1 avril 2017

Pagination : 196-197

ISBN : 978-2-919040-38-4

ISSN : $1142-852 X$

\section{Référence électronique}

Mustapha Harzoune, « Gaël Faye, Petit pays », Hommes \& migrations [En ligne], 1317-1318 | 2017, mis en ligne le 01 avril 2017, consulté le 10 décembre 2020. URL : http://journals.openedition.org/ hommesmigrations/3937; DOI : https://doi.org/10.4000/hommesmigrations.3937 


\section{LIVRES}

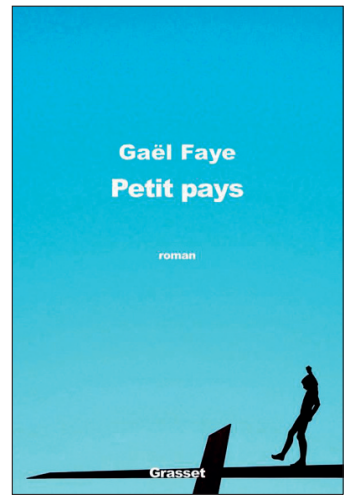

\section{Gaël Faye}

Petit pays

Paris, Grasset,

2016, 217 p., $18 €$.

Gaël Faye, connu comme auteur-compositeurinterprète, a fait une entrée fracassante en littérature. Après s'être baguenaudé sur les listes de tous les prix littéraires, Petit pays s'est vu gratifié du Goncourt des lycéens, du Prix du roman Fnac, du Prix du premier roman et du Prix des étudiants France CultureTélérama. L'engouement est-il justifié ? Petit pays est certes un bon roman mais, sur le sujet, il en est d'autres servis dans un bouillon plus épais. Il en est d'autres plus exigeants - et il se peut que ce soit ce qui pêche pour des lecteurs par trop pressés et que le corps sans vie d'un gamin sur une plage turque ou l'adorable museau d'un chaton sur Internet attendrit illico. Mais fissa! On zappe d'un livre l'autre, d'une émotion l'autre. Le succès de Petit pays, nullement immérité, n'interdit pas de questionner les ressorts d'un si unanime enthousiasme, injuste peutêtre pour d'autres romans, au moins aussi méritants.

II est vrai que Gaël Faye réussit une performance d'écriture. II raconte la guerre au Burundi et le génocide des Tutsis au Rwanda, avec les yeux et les mots de Gabriel, un gamin de onze ans. La phrase est limpide, fluide, souvent descriptive. Des mots simples embarquent le lecteur dans le paradis perdu de l'enfance, restituent les sons, les couleurs, les musiques d'un temps disparu. Des mots justes pour dire l'intime, les émotions de Gabriel (peur, culpabilité, jalousie ou courage) ou l'agonie d'Yvonne. Des mots touchants, poignants, mais sans pathos, pour raconter les drames de l'Histoire (massacres collectifs ou mort d'un malheureux, au coin d'une rue ou à l'intérieur d'une voiture).

Ana et Gabriel sont les enfants métis d'Yvonne et de Michel. Une Tutsie et un Français du Jura, une Noire et un Blanc... Si cela ne va pas de soi en France - «Ma peau caramel est souvent sommée de montrer patte blanche en déclinant son pedigree "-, cela est encore plus problématique dans cette partie de l'Afrique où les inimitiés se doublent d'ingérences, françaises en l'occurrence, discutables et même néfastes - il le dit ou le fait dire.

Entre des parents désunis, une guerre civile et des appartenances multiples, Gabriel se fabrique des repères avec ses copains de l'impasse : les deux jumeaux, Armand et Gino " son frère ". La bande se tient chaud. Mais les velléités identitaires de Gino, flanqué de Francis, un ancien mayibobo (gosse des rues), transforment le quartier « en forteresse " et l'impasse " en enclos". " Je me demande encore quand, les copains et moi, nous avons commencé à avoir peur. " C'est Camus en culotte courte au milieu d'ados qui se la jouent adultes. "Pour la première fois de ma vie, je me sentais à l'étroit dans l'impasse, cet espace confiné où mes préoccupations tournaient en rond. " Gabriel puisera dans la bibliothèque de Mme Economopoulos de 
quoi s'aérer et faire reculer l'horizon. "Un livre peut te changer [...] il faut se méfier des livres, ce sont des génies endormis".

Efficaces, les formules et les images frappent. Exemples, sur le métissage (" je tangue entre deux rives, mon âme a cette maladie-là ») ou le génocide ("le génocide est une marée noire, ceux qui ne s'y sont pas noyés sont mazoutés à vie »). Éloge aussi de la littérature à propos de réfugiés et de leurs enfants : "L'opinion publique pensera qu'ils ont fui l'enfer pour trouver l'Eldorado. Foutaises ! On ne dira rien du pays en eux. La poésie n'est pas de l'information. Pourtant c'est la seule chose qu'un être humain retiendra de son passage sur terre. Je détourne les yeux de ces images, elles disent le réel, pas la vérité. Ces enfants l'écriront peut-être, un jour ».

Le récit s'ouvre sur le retour de Gabriel au Burundi. L'adulte qu'il est devenu va faire la part du réel et de la vérité.

M. H.

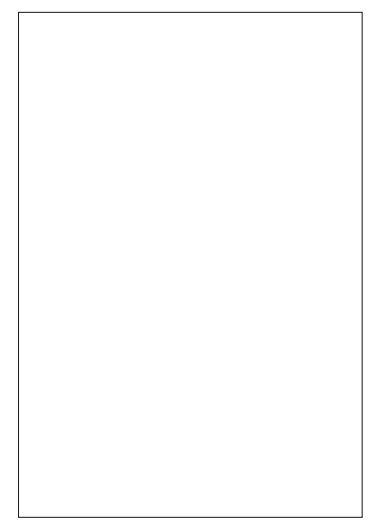

\section{Nathacha \\ Appanah}

Fropique

dela violence

Paris, Gallimard, zo16, 177 P., $17,50 €$

Âmes sensibles s'abs= tenir! Pourtant, ce Fropique de laviolence se situe en France, dans f'enfer de Mayotte, à fintersection de trois solitudes, trois façons de survivreMarie est infirmière; obsédée, dévorée, broyée, entaidie - chaque année, ehaque mois, un peu plus - par un désir inassouvi de maternité : "Quand vient te sang chaud dans ma culotte chaque mois, je pleure et je maudis toutes ees mères que je vois ì l'hôpital qui ne connaissent rien ì rien, toutes ces clandestines venues accoucher sur eette île française pour des papiers [...]. Je change, j'enfle mais il n'y a que dela mauvaise graisseen moi, ma tête tourne et mes paroles virent à l'aigre comme du lait. "Elle-finit par entever et adopter le bébé d'une clandestine: tenfant a un ceil noir et un œil vert. Pour sa mère, il est l'enfant du djinn. I porte malheur!

Mö̈se est le fils abandonné. À l'adotescence, il veut connaitre son histoire. Fourmenté, it se détoume de celle qu'it nappette plus Mam mais Marie." IIme dit que je l'ai élevé comme un Blanc, que je l'aiempêché de vivre sa "vraie vie" "Le gamin rejoint ceux qu'il croit être les siens: les clandestins. II n'emporte qu'un livre, t'enfant et la rivière, et un sac à dos, celui de Marie, qui lui sert d'oreiller." Quand j'ai su la vérité, je me suis sentiun moins que rien, une merde, un gosse qui a fait peur ì sa propre mère quand il est sorti d'elle, un gosse qu'elle a donné au premier venu, comment appeler cela? $\pi$ Brutal et impitoyable, Bruce se revendique pur Mahorais, descendant d'esclaves, en rage contrela société. "Parce que tucrois que je suis né comme ça, 